\section{Lending and Borrowing Across Borders} Issues and

Challenges with International Resource Sharing
Sharing and Transforming Access to Resources Section International Interlibrary Loan Committee

Contributing Sharing and Transforming Access to Resources Section (STARS) International Interlibrary Loan Committee members: Tina Baich, Tim Jiping Zou, Heather Weltin, and Zheng Ye Yang.
$\mathbf{T}$ he charge of the RUSA Sharing and Transforming Access to Resources Section (STARS) International Interlibrary Loan Committee is to evaluate trends in international interlibrary loan (ILL) and resource sharing, to develop materials and resources for international ILL practitioners, and to promote international ILL resource sharing efforts. In 2006, the committee decided to survey U.S. libraries regarding their international ILL activities as a way to gather information on the current environment and identify strategies for improving international ILL. The survey was deployed in the spring of 2007. In the fall of 2008, the committee members drafted an executive summary, which was approved by the RUSA STARS Executive Committee and posted to the STARS website (www.ala.org/ala/mgrps/ divs/rusa/sections/stars/section/internationill/ILLReport ExecSummary.pdf).

Specifically, the survey sought to determine what types of U.S. libraries participate in international ILL services as borrowers and lenders, to what extent libraries work internationally, and what tools and services survey participants use to go global. The results of the survey will help guide the committee in developing tools to resolve issues that may hinder international resource sharing and uncover opportunities to promote and expand both the use of and the participation in global ILL services. This article intends to reflect on changes in the resource-sharing environment since 1998, provide an overview of current practice, and lay the foundation for future International Interlibrary Loan Committee efforts.

\section{LITERATURE REVIEW}

Libraries in the United States and abroad have engaged in some level of international ILL for more than one hundred years. In the early 1900s, the Library of Congress began lending to other national libraries. International ILL grew slowly in the early decades of the twentieth century, but came to an abrupt halt during World War II. In the years following, U.S. libraries were reluctant participants in international ILL. This changed in 1959 with the American Library Association's ratification of the International Interlibrary Loan Procedure for United States Libraries. ${ }^{1}$ Despite this long-standing practice and earlier adoption of procedures, the ILL community still lacks formalized efficient methods for conducting international transactions. Over the past several decades, international ILL has become a larger issue because of the rapidly changing information environment we face.

The ease with which library patrons are able to locate international resources is constantly growing. Anyone can easily locate the online catalog of an international library. It 
is also increasingly common to find international holdings in OCLC's WorldCat regardless of whether those libraries participate in international lending. Our patrons are not aware of the difficulties in obtaining these resources. When they request items, they expect to get them. With the speed of new technology, our users are accustomed to instant gratification in their information seeking.

In addition to increased patron expectations, the inverse relationship between inflating materials costs and decreasing materials budgets necessitates a closer look at international ILL practices. With higher prices and more publications with less to spend, many libraries are being forced to turn to resource sharing for materials they previously would have purchased.

As a result, ILL practitioners increasingly express frustration over the lack of coherent procedures and communications methods and seek ways of improving international cooperation. In 2002, Robert Seal clearly delineated many of the challenges of international ILL:

(1) inadequate human resources to carry out interlibrary loan, especially on an international scale; (2) insufficient funding which prevents starting and sustaining collaborative projects; (3) out-of-date computer technology, incompatible systems, and poor telecommunications infrastructure; (4) a lack of international standards for bibliographic description, record format, and exchange of data; (5) copyright issues; (6) insufficient information about foreign holdings; (7) a lack of knowledge about methods of access, regulations and policies abroad; (8) negative attitudes or mistrust; (9) lack of resource sharing tradition; and (10) an unwillingness to share limited resources which could be lost or damaged. ${ }^{2}$

As the results of the committee's survey showed, many of these challenges still exist or are perceived to exist. The need to solidify international ILL practices is thus important to improving our service and making our departments more efficient and effective.

Current documentation of ILL best practices should be used as a model for international ILL standards. A number of such documents exist and have begun to address some of the obstacles outlined by Seal. The Interlibrary Loan Code for the United States, maintained by the RUSA STARS Interlibrary Loan Committee, was originally adopted in 1994. Revised in 2008, it continues to guide U.S. ILL practices. ${ }^{3}$ Rather than maintaining a separate document regarding international ILL, the code defers to the International Federation of Library Associations and Institutions' (IFLA) International Lending and Document Delivery: Principles and Guidelines for Procedures. IFLA's document comprises eight principles, which are reinforced by accompanying guidelines. ${ }^{4}$ The U.S. ILL code and IFLA's guidelines both cover the responsibilities of requesting and supplying libraries. IFLA provides more extensive guidelines for copyright and payment issues, two of the major obstacles identified in developing international cooperation between libraries.

Regional groups also have endeavored to create standards, as demonstrated by the Greater Western Library Alliance (GWLA) Task Force on Interlibrary Loan. This organization's best practices report, last updated in 2004, is organized into three levels: conceptual, structural, and procedural. ${ }^{5}$ This structure emphasizes the need to keep an eye on the big picture of interlibrary services. Not only must we standardize day-to-day procedures, we also must create a common vision of resource sharing.

Elkington and Massie discussed the history of international interlending in the United States and United Kingdom since $1900 .{ }^{6}$ While international ILL did occur in the early twentieth century, it lacked the formalization we are now trying to achieve. In the late twentieth century we saw advances such as the International Standards Organization (ISO) ILL Protocol. This protocol provides for standard messages to be sent between libraries and has incited an increase in standards-compliant software, such as OCLC WorldCat Resource Sharing and ILLiad. ISO-compliant ILL operations have an advantage in the international ILL arena because of the inherent compatible communications infrastructure created in the ISO ILL Protocol.

The efforts of the STARS Rethinking Resource Sharing Initiative (RRSI) are parallel to the goals of the International ILL Committee. A major focus of the RRSI is global visibility of materials. This is an essential step in building global access to the same materials. As Wanner, Beaubian, and Jeske aptly state, "As libraries are making their collections visible on a global scale, so should they provide an international resource delivery system or a service model that combines the strengths of all participating libraries." ${ }^{\text {"7 }}$ Despite our joint recognition of this need, obstacles still exist in achieving this goal. The International ILL Committee hopes that through collaborative efforts with RRSI, IFLA and others solutions can be developed to address the barriers identified in its survey, which are discussed in this article.

\section{RLG INTERNATIONAL ILL TASK FORCE SURVEY, 1998}

Prior to its merger with OCLC, the Research Libraries Group (RLG) initiated efforts to standardize international resource sharing through its International ILL Task Force. The task force surveyed members of the RLG SHARES group in 1998 to assess the extent of international ILL as well as the fears and needs of group members regarding international ILL. The study gathered data on the international ILL transactions of RLG SHARES partners. Of the 85 invited institutions, respondents consisted of 19 U.S. university libraries, 7 U.S. museum libraries, 5 U.S. law libraries, 5 Consortium of University Research Libraries (CURL)/RLG UK university libraries, 1 Canadian university library, 1 Italian museum library, and the Australian National Library for a total of 41 (according to the study) participants. ${ }^{8}$ The results of the study confirmed the 


\section{FROM COMMITTEES OF RUSA}

task force's expectations of prevalent perceptions among RLG SHARES members that "engaging in international interlending would increase costs, would put library materials at greater physical risk of loss or damage, that the time and distance paradigm would result in a decline in the quality of service to the user, and that there might be a negative shift in user perceptions of interlending and document supply." The task force also found the following: that the demand for international ILL was strong even though the number of transactions was comparatively low; that international ILL traffic would increase as the bibliographic discovery environment was improved; and that not all SHARES members were interested in international interlending. The authors of the report further noted that "twenty percent of the survey respondents were not interested in conducting ILL with international SHARES partners" because of the combined impediments of lack of demand, complicated procedures, and high cost of shipping returnable materials. Therefore, many would be interested only in requesting or providing nonreturnable materials. ${ }^{9}$

How much would it cost to ship a returnable item to an international library? Massie specified that to ship a two-pound book from Ithaca, New York, to London would cost more than $\$ 20$ via the U.S. Postal Service's registered airmail, more than $\$ 30$ via Federal Express or Airborne, and more than $\$ 40$ via United Parcel Service compared to less than $\$ 5$ to ship the same parcel from Ithaca to Palo Alto, California. What were the total transactions during the surveyed period? From July 1998 to April 1999, 15 international SHARES libraries borrowed 2,903 items from the U.S. SHARES libraries compared to 467 items loaned to the U.S. SHARES libraries. As borrowers, non-U.S. SHARES libraries received returnable items in about 12 days (including weekends and holidays). As lenders, non-U.S. SHARES libraries' turnaround time was about 8.5 days. Massie thus observed the following trends:

- Non-U.S. SHARES libraries borrowed six times more returnable items from the U.S. libraries than they loaned to U.S. libraries.

- U.S. SHARES libraries' fill rate for borrowing requests was 49 percent whereas non-U.S. SHARES libraries' fill rate for borrowing requests was 64 percent.

- The farther an international SHARES institution is from the United States, the higher the proportion of nonreturnable materials it received. ${ }^{10}$

RLG Task Force's study focused only on RLG member libraries, but in many ways served as a forerunner for this study and offered many interesting points of comparison for this paper.

\section{RUSA STARS SURVEY, 2007}

At the 2006 ALA Annual Conference in New Orleans, the RUSA STARS International Interlibrary Loan Committee decided to create a survey to assess the state of U.S. international ILL services. Specifically, the committee wanted to uncover from the survey results opportunities to promote and expand both the use of and the participation in global ILL services. The survey was divided into sections that concentrate on bibliographical discovery tools and processes, communication methods through which requests are transmitted and exchanged across borders, methods of payments and fees, and methods of delivery and shipment. As this is a broad study of all the key elements pertaining to international ILL, the survey's focus is different from that of the RLG 1998 survey. However, the former offers a helpful reference against which the current international ILL environment can be compared.

\section{Demographics}

The RUSA STARS International Interlibrary Loan Committee survey targeted only U.S. libraries that provide either or both international borrowing or lending. Libraries that did not have international interlibrary activities were excluded. Survey questions were distributed via four major national ILL discussion lists to reach all types of libraries in various resource-sharing networks. The committee received responses from 157 libraries, of which 88 (52 percent) were academic libraries; 66 (39 percent) were medical or special libraries; and 15 (9 percent) were public, law, or state libraries. Twelve participants chose more than one type of library. Therefore the RUSA STARS survey has almost four times the participants as the RLG 1998 survey, which was limited to 40 SHARES partner libraries consisting of 31 (77 percent) academic and special libraries in the United States and 9 (23 percent) international libraries in the United Kingdom, Canada, Italy, and Australia. RLG SHARES libraries are mostly large, comprehensive libraries. RUSA STARS survey participants, on the other hand, are more diverse in the type and size
Number of Libraries-Lending

Returnable

$81(52 \%)$

$65(41 \%)$

$42(27 \%)$

$22(14 \%)$

$15(9 \%)$

$12(8 \%)$

$1(1 \%)$
$8(5 \%)$

$4(2)$
$19(12)$

$14(9 \%)$

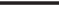

Annual Transactions

$<1,000$

$1,000-5,000$

$5,000-10,000$

$10,000-20,000$

$20,000-40,000$

$>40,000$
Number of Libraries-Borrowing

Returnable

$83(53 \%)$

$31(20 \%)$

$60(38 \%)$

$47(30 \%)$

$26(17 \%)$

$34(22 \%)$

$10(6 \%)$

$4(3 \%)$

$3(2 \%)$
$7(4 \%)$

$0(0 \%)$ 
of interlibrary loan operation in terms of overall interlibrary loan transactions (see table 1). We believe that the RUSA STARS survey results should be more representative of the general situation of international borrowing and lending in the United States.

\section{Activities and Restrictions}

The STARS survey results presented a more favorable environment for global resource sharing than six years ago. Today many U.S. libraries are willing to loan materials internationally, and the demand for borrowing materials from overseas is increasing. Of the 157 responding libraries, 147 (94 percent) confirmed that they both borrowed and lent internationally. Also positively different from the RLG survey results was that 68 percent of STARS respondents confirmed that they supplied both returnable and nonreturnable materials to international libraries compared to 66 percent that borrowed both returnable and nonreturnable items from overseas. Seventy percent of STARS respondents confirmed that they would not charge additional fees for lending materials to non-U.S. libraries.

Several factors that limited the scale of international ILL were identified. From respondents' comments we inferred that their annual international ILL transactions made up a relatively small portion of their overall activity because they generally found what they needed domestically. Approximately 30 percent of respondents indicated that they only borrowed and lent nonreturnable materials internationally because of higher international shipping costs and longer delivery time. For the same reasons, some indicated that they only borrowed returnable materials from libraries in Canada and Mexico, but would be willing to loan returnable materials to international libraries in other countries. Some respondents reported difficulty in locating international lenders because they found most international libraries were not OCLC suppliers. Some U.S. academic libraries allow international ILL borrowing only if the requested materials are needed to support certain identified research areas that are either very special or unique to their campuses.

While many U.S. libraries are willing to lend internationally, they are not always quite prepared for this endeavor. Fifty-one percent of survey respondents said they either were not listed or were not sure if they were listed as an international lender in the OCLC ILL Policies Directory. Being listed as an international lender is important so international libraries can easily determine where to send requests. Therefore about half of the respondents need to update their OCLC ILL Policies Directory profile to provide better information for international ILL.

Patterns of international ILL traffic were recognized from the survey results. Canada, Australia, Great Britain, Demark and Japan (in a tie with South Africa), New Zealand, and Mexico were among the top countries from which U.S. libraries received the most borrowing requests (see figure 1 ).

In the RLG SHARES's study, it was observed that the quantity of lending to international libraries was proportionally correlated to the geographic proximity of the requesting libraries. ${ }^{11}$ The STARS survey results seemed to support this statement in the case of Canada, but not in the case of Mexico. Several respondents went as far as to say that they would not lend returnable materials to any country other than Canada because of cost and difficulty in shipment.

Language and economic status also seem to be determining factors as the majority of the list are English speaking countries, with the exceptions of Japan, Mexico, and Denmark (English as the second major language), and are economically developed countries, with the exception of Mexico. These developed countries all have more advanced nationwide library and information networks that promote international information resource sharing either by contributing bibliographic records to OCLC WorldCat or obtaining access to U.S. bibliographic records for their local users from OCLC. Currently, OCLC WorldCat contains 76.2 million holdings from about 34 non-U.S. national libraries. Many developed countries have already established partnerships with OCLC and used the WorldCat Resource Sharing as the platform for international resource sharing. The national library networks in Great Britain, Canada, Australia, New Zealand, and Japan all use OCLC interlibrary service to share resources with U.S. libraries. ${ }^{12}$

An identical pattern was observed in the case of international borrowing requests made by the U.S. libraries (see figure 2).

Generally, U.S. libraries do not impose greater restrictions on material types they will lend internationally. Some libraries apply the same policies for domestic interlibrary lending, 


\section{FROM COMMITTEES OF RUSA}

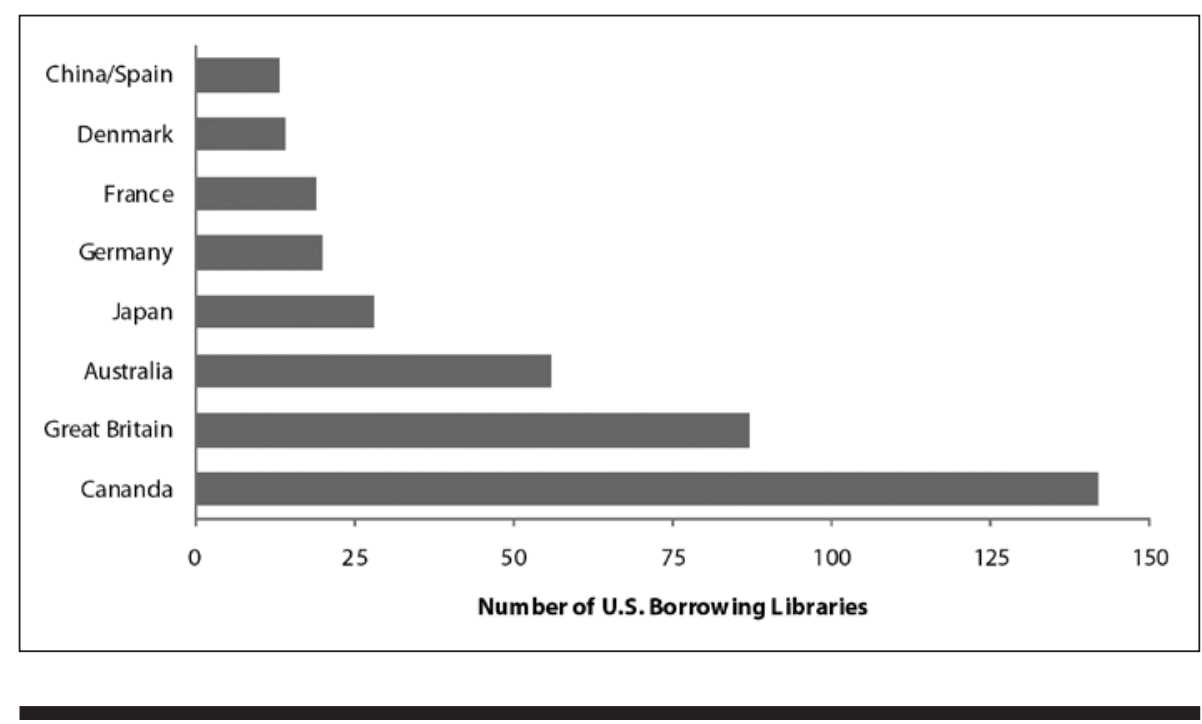

Figure 2. Top Eight Countries Lending to U.S. Libraries

while some prefer to review international requests on a caseby-case basis to assess local demand for the requested materials. For many respondents, shipping costs were the major factor that negatively affected a U.S. library's willingness to loan a particular item. If shipping costs were not a concern, they would be very willing to lend materials based on a reciprocal agreement. Many U.S. libraries would be more willing to lend paper copies through fax or scanned articles as e-mail attachments to the small international libraries that do not have much ILL and document-delivery technology.

\section{Bibliographic Discovery}

International ILL faces numerous challenges, and perhaps one of the most difficult is citation verification. It is often difficult to locate lending libraries internationally, and when one finally does it is even more difficult verifying citations and checking holdings because of technological and language barriers. The 1998 RLG study reflects this difficulty in its finding that U.S.-UK ILL transactions would increase as bibliographic tools improved. ${ }^{13}$ The STARS respondents also expressed problems with citation verification, communication, and submitting requests.

When libraries request materials internationally, it can be a time-consuming process to verify citations and holdings. However, this practice reduces the risk of further delays and problems. The 1998 RLG survey found that declines in fill rates between borrowing and lending could frequently be attributed to inaccuracy of citations received. ${ }^{14}$ Not surprisingly, the majority of borrowers in the STARS survey (67.5 percent) responded that they routinely verified citations prior to sending requests internationally. Lenders were almost equally divided between those who routinely attempt to verify requests they receive (39 percent) and those who never do (40 percent). Although the survey did not allow for additional comment, the committee speculates that many lending libraries do not engage in citation verification because, according to the various ILL codes, the onus of verification falls on the borrowing library. ${ }^{15}$ With technological, language, and other barriers already hindering successful international ILL, taking the initiative to verify citations prior to sending them becomes almost essential to speed up the entire process; however, it is recognized that this is not always feasible because of language barriers.

Verifying holdings at an international library is another way to make sure that a request is not delayed because the library receiving the request lacks it. An impressive percentage of our borrowing respondents (86 percent) said that they do attempt to verify holdings prior to sending them to an international library. While the survey did ask respondents where they locate holdings, it did not ask how or to what extent. Therefore we cannot be sure what level of effort borrowing libraries exert to verify holdings. Do they check a library's catalog? Do they rely on holdings listed elsewhere? Regardless, this preemptive step becomes important because of the time it can take to send and receive materials when requesting internationally.

Even though our respondents represented several different types of libraries, trends emerged regarding the resources used to locate and obtain materials from international lenders. An overwhelming number of respondents listed online resources, especially Google, as their preferred method for locating international holdings. The Internet and some national catalogs were named by respondents, slightly below a library's catalog (OPAC) or website. ${ }^{16}$ This is not surprising considering the shift toward reliance on online resources and the fact that more ILL requests seem to be located and submitted through online resources than ever before. Although many respondents relied on library catalogs to locate holdings, very few actually called lenders for verification. Print resources like the National Union Catalog, a pre-1950s catalog of libraries' holdings throughout the United States and Canada, were also mentioned. Respondents also relied on colleagues, information obtained from discussion lists, individual e-mail, and wikis such as ShareILL. ${ }^{17}$ Finally, among all of the tools used, WorldCat, OCLC's comprehensive catalog of U.S. and international libraries holdings, was listed twice as much as any other tool. ${ }^{18}$

Participants also had similar responses when asked which gateways and projects they used for citation and holdings verification. Interestingly, several respondents were not familiar with the two examples provided in the question, the Gateway Service Center of Chinese Academic Journal Publications and the Global ILL Framework. However, both of these were also 
listed by a majority of other respondents as the projects they find most useful, along with several of the same resource catalogs listed in the previous paragraph. Some of the most cited gateways and projects were the following:

- Gateway Service Center of Chinese Academic Journal Publications, which provides free delivery of full-text Chinese language academic publications not held in U.S. libraries. ${ }^{19}$

- The Global ILL Framework (GIF), which is defined on their website as a "reciprocal agreement between North American and Japanese academic libraries and research institutes to provide North American researchers with access to materials not available through normal ILL channels." ${ }^{20}$

- The British Library, which offers numerous services to aid in international ILL. Some of these include research services, document supply, and access to electronic dissertations. ${ }^{21}$

- DOCLINE, which is the "National Library of Medicine's automated interlibrary loan (ILL) request routing and referral system." One of their goals is to improve document delivery between their members, many of which are medical libraries. ${ }^{22}$

- National catalogs such as Canada Institute for Scientific and Technical Information (CISTI), COPAC, and Karlsruhe Virtual Catalogue (KVK). ${ }^{23}$

\section{Communication}

An issue related to citation and holdings verification is communication. Language barriers and technological or system differences often play a critical role in international requesting and can increase the time between submitting and receiving a request. Again, respondent answers were very similar, but some key observations can be made by comparing the responses to each question regarding communication methods.

When asked what contact method(s) they use to submit and receive international borrowing requests, respondents most commonly selected OCLC for both submitting (29.4 percent) and receiving (26.1 percent) requests. Closely following was e-mail (28.9 percent submitting, 24.6 percent receiving). More "traditional" methods like fax, phone, and mail rated much lower. The lower number of respondents selecting these methods may be attributed to two factors: (1) These types of requests cause delays and can increase turnaround times for borrowing libraries; (2) The majority of our respondents may be using OCLC or another ILL software and rarely use these types of requesting options unless necessary. Respondents choosing "other" generally indicate DOCLINE or webpages as preferred options.

Surprisingly, when asked what contact method(s) they prefer to use to submit and receive international requests, respondents most commonly chose e-mail (36.4 percent submitting, 34.7 percent receiving) rather than OCLC (32.5 submitting percent, 32.1 percent receiving). Though the percentages are close, when compared to what they actually use, the responses indicate that U.S. libraries are not always able to use their preferred requesting method. While the survey did not ask lenders to specify why they would prefer e-mail, we offer the following hypotheses as to why this is the case: international libraries may not use OCLC, making this submission method impossible; and, in addition to technological issues, language barriers may make it difficult to use alternate methods of submitting requests. As above, more "traditional" methods ranked lower as preferred methods for both sending and receiving requests.

It is worth noting that the two request methods designed specifically with international ILL in mind, IFLA forms and ISO messaging, ranked last in both used and preferred methods of communication. ${ }^{24}$ In terms of use, 4.6 percent of respondents reported using IFLA forms to submit requests while 8 percent indicated receiving requests via this method. ISO messaging ranked even lower with 2.5 percent reporting submitting requests, and only 2 percent reporting receiving requests using this method. In terms of preference, these options rank even lower. IFLA forms are preferred by 1.5 percent of respondents for submitting requests, while 1.1 percent prefers receiving requests via this method. ISO messaging is preferred by 1.8 percent of respondents for submitting requests, and 1.1 percent prefer receiving requests using this method.

\section{Payment Methods}

One of the barriers identified by previous studies involved how to bill and pay for international ILL transactions. Having to deal with currency exchange rates and complying with local or institutional accounting regulations all add stress to the workload of ILL departments. To seek ways to overcome these barriers, Christine Robben and Cherié L. Weible describe six payment options available for consideration. These methods are signing a reciprocal agreement with an international library, managing standard invoices, using deposit accounts, the IFLA Voucher Scheme, International Reply Coupons, to OCLC Interlibrary Loan Fee Management (IFM). ${ }^{25}$

Today, the most widely accepted and effective method of ILL payment by and among various resource sharing groups in the United States is OCLC IFM, which acts like an outsourced fee management system for member libraries. OCLC IFM tracks the debit and credit activities of member libraries through a monthly report and therefore alleviates the burden of managing invoices and payments for each transaction. As a borrower, a member library specifies a maximum cost in U.S. dollars they are willing to pay through IFM within a request. Generally, a library will request items from noncharging, or reciprocal, libraries first. If a noncharging library fills a request, no IFM fee is charged. For a charging, or nonreciprocal, library to fill the request, its standard charge must either fall below or equal the maximum cost indicated by the borrowing library or it must notify the library of the higher charge 


\section{FROM COMMITTEES OF RUSA}

and receive permission from the borrowing library in order to fill the request. Any charges are then processed through IFM.

Two similar nationwide ILL fee management systems that operate in a similar manner are also worth mentioning. DOCLINE's Electronic Funds Transfer System (EFTS) is a transaction-based electronic billing system developed by the University of Connecticut Health Center and used by members of the National Network of Libraries of Medicine to manage ILL and document delivery charges between DOCLINE libraries. RLG SHARES was another major resource-sharing group network that helped its member libraries with a fee management tool. After RLG merged with OCLC in 2006, the fee management utility was transferred to the OCLC IFM platform.

While OCLC WorldCat Resource Sharing (WCRS) has increasingly become a global platform, not all international libraries, particularly those in developing or underdeveloped countries, are ready for or can afford membership in WCRS. Additionally, international borrowing and lending transactions by those libraries are so sporadic and irregular that those libraries may find IFLA vouchers, International Reply Coupons, or reciprocal agreements with selected libraries serve their needs. Our survey results, however, show that U.S. libraries most prefer receiving payment via OCLC IFM. When dealing with payment from international libraries that do not use IFM, U.S. libraries then prefer U.S. bank checks and reciprocal agreements over other methods. While credit cards are accepted as a standard payment method by commercial document suppliers or fee-based European national document delivery services, they have not become a universally accepted method of payment for interlibrary transactions among U.S. libraries. Only 8 percent of respondents accepted this method. Figure 3 shows the overall ranking of payment methods accepted by U.S. libraries.

U.S. libraries that did not use any of the listed payment methods generally did not charge international libraries for a variety of reasons, including unwillingness to deal with payments made via non-U.S. banks, honoring "free for all" agreements such as "FreeShare," or only charging those who would charge to lend to U.S. libraries. ${ }^{26}$ Many respondents indicated that they would generally prefer to lend or borrow on reciprocal agreements with selected international libraries so that the libraries were only responsible for shipping costs.

The majority of respondents were willing to accept a variety of payment methods in order to provide services to international libraries. However, several issues that make receiving international payments difficult were brought to light:

Many U.S. institutions do not accept payment in nonU.S. currency.

- Some U.S. libraries are not capable of accepting electronic fund transfers nor do they have a specific account ready for that type of payment.

- Difficulties in matching a payment to a specific ILL transaction, especially when money is wired to a library's bank account.

- When payments were electronically transferred to a university account, the local ILL office was not notified and therefore unable to credit the payments.

- Payments were made in forms other than methods specified as acceptable by the lending library (i.e., coupons, IFLA vouches, or credit cards).

- Late payments and lengthy delays in receiving payments made it very time-consuming to monitor and track the payments.

As borrowers, 60.5 percent of survey respondents use OCLC IFM whenever possible. If OCLC IFM is not an option for an international library, the next four most used payment methods are U.S. bank checks (52.9 percent), credit cards (31.2 percent), IFLA vouchers (29.3 percent), and reciprocal agreements (28.7 percent). It is interesting to notice that for this group of libraries, DOCLINE EFTS, RLG SHARES, and foreign bank checks were among the least used methods of payment. Figure 4 shows the overall ranking of payment methods used by U.S. libraries.

Overall, U.S. libraries prefer to leave payment in the hands of a payment management utility such as OCLC IFM or DOCLINE EFTS. If neither is acceptable by an international supplier, they prefer to not deal with charges and payments by entering reciprocal agreements, or, if necessary, pay with U.S. bank checks or credit cards. Other methods are not considered as desirable or convenient to them. Among the problems with making international payments highlighted by 


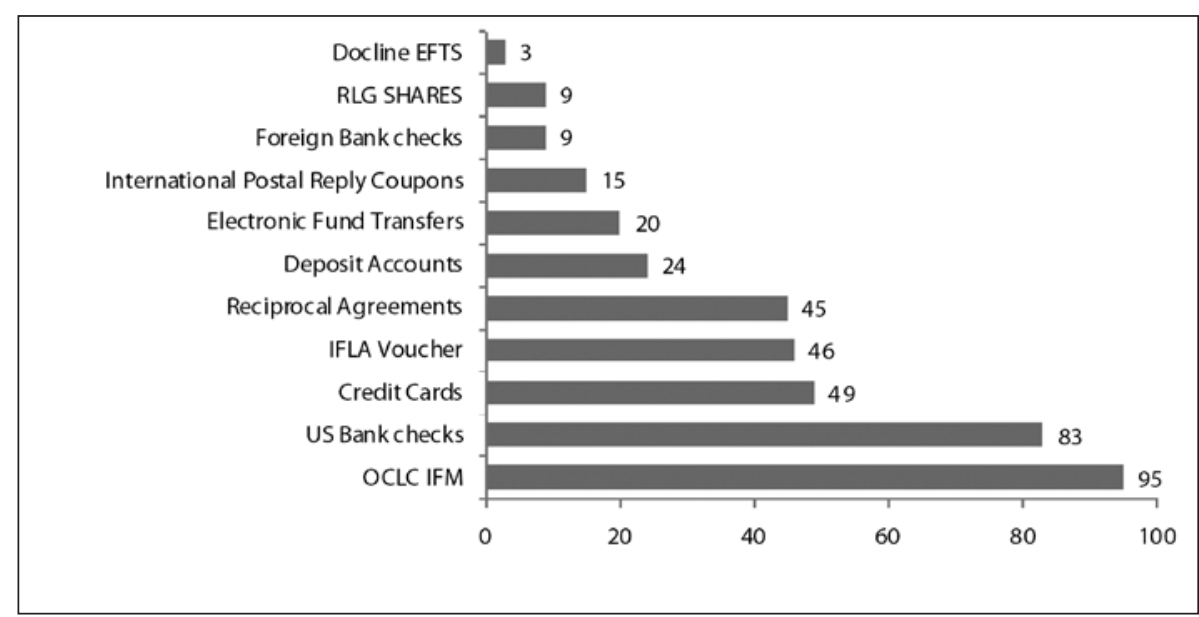

Figure 4. Number of Libraries Able to Pay Using Each Method

respondents were the following:

- Limitations on payment options for them as borrowers, especially if a lender could not accept OCLC IFM, DOCLINE EFTS, or checks drawn from U.S. banks.

- Checks, if they were required, took a longer time to be issued and sent.

- Requirement of prepayment before requests were processed.

- Currency fluctuations that made it difficult to send a check to "the right place on time and for the right value."

- Invoiced amounts for borrowing an item were smaller than the fees for electronic funds transfers.

\section{Shipping and Delivery Methods}

The cost associated with shipping a book to a borrower overseas is significantly higher than shipping it to a borrower in the United States. Mary Jackson's 2002 study confirmed that the delivery cost for U.S. libraries as a percentage of the average borrowing unit cost for mediated interlibrary loan service was 5 percent of $\$ 17.50$ for borrowing and 13 percent of $\$ 9.27$ for lending. That average delivery cost calculation included costs for Ariel/electronic delivery, commercial delivery services, courier services, fax, postal service, and other miscellaneous costs. The calculation of the average borrowing unit cost included staff, network, delivery, photocopying, supplies, equipment, and borrowing fees; the average lending unit cost included all the aforementioned elements except borrowing fees. ${ }^{27}$

Currently, the majority of libraries deliver nonreturnable materials in digital format via Ariel or Odyssey and returnable materials through a mix of delivery services consisting of state, regional, or consortial courier services, USPS, and other major commercial delivery services. A consortial courier service usually requires a participating library to pay a flat annual fee to cover an unlimited number of deliver- ies. Therefore consortial courier services help drive the portion of the delivery cost down. Jackson's study noted that the portion of the delivery cost in the ILLNET unit cost was only 1 percent, which is a big savings for ILLNET library consortial members. ${ }^{28}$

Shipping and delivering a returnable item overseas is a different story. The 1998 RLG study found that the cost for the delivery of the same item to an international borrower in London could be 3 to 5 times as expensive as delivering it from the same U.S. supplier to a borrower in the U.S. Because of this, "lenders are often reluctant to absorb such costs. ${ }^{29}$ In addition to the formidable costs are the longer delivery time associated with greater geographic distance, possible customs delays, and the fear that materials shipped overseas might be "out of the reach of local constituents for an unacceptably long period of time." ${ }^{30}$ In a June 1998 survey conducted on the ILL-L discussion list, Massie found that less than 25 percent of surveyed U.S. libraries used commercial couriers for shipping returnable items to international borrowers. The two commonly used commercial courier services then were Federal Express (FedEx) and UPS. Both services, however, were rated unfavorably on their prices. Additionally, the surveyed RLG libraries particularly did not like the delay of UPS shipments at customs and the exasperating forms used by FedEx. ${ }^{31}$

In August 1998, the RLG International ILL Task Force began negotiating a group international shipping discount for SHARES member libraries modeled on a national shipping discount trial between U.S. libraries and FedEx conducted from 1995 to 1997. After twelve months of negotiation, the task force failed to find a carrier willing to enter into a group discount deal because "no company seemed very bothered about the comparatively low level of business on offer." 32

The STARS survey revisited these issues by asking respondents about their use of four major shipping and delivery services-DHL, FedEx, UPS, and USPS—for sending returnable or nonreturnable materials outside the United States. USPS was the most frequently used (49.2 percent); FedEx (4l percent) and UPS (40 percent) were the second and third. Only 3.6 percent of the respondents said they used DHL, and 5.2 percent said they also used other service options. Thirty-six respondents said they used more than just one of the four services. For those who selected "other" as an answer, their explanations were either that they did not lend or borrow returnable items outside the United States, only deliver scanned articles via e-mail in PDF format, or used the carriers their international borrowers specifically requested. Figure 5 shows the number of libraries using each carrier.

Most respondents indicated the benefits of using USPS 


\section{FROM COMMITTEES OF RUSA}

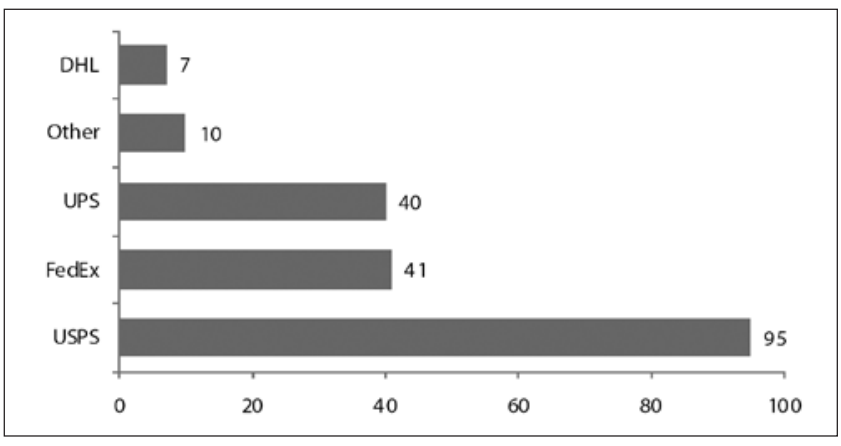

Figure 5. Number of Libraries Using Each Carrier

are convenience and price. Twenty-three respondents also considered help with customs a benefit to using USPS. The delivery speed and the inability to track international package deliveries were mentioned as two major drawbacks of using USPS. Of the three remaining carriers, speed, tracking, and reliability were the primary benefits, which happened to be the three primary drawbacks of using USPS. The two primary drawbacks for FedEx, UPS, and DHL were price and paperwork. Unlike the RLG 1998 survey results, respondents in this survey did not mention increased customs problems associated with UPS shipments.

When asked to offer tips on simplifying shipping returnable materials internationally, the following were among respondents' suggestions:

- Always ship via air mail (it can take up to 8 weeks by boat).

- Always use first class USPS for faster delivery to Canadian libraries.

- Ask international borrowers to include preferred shipping method for receipt and return of materials.

- Double check addresses or get preprinted shipping forms to avoid mistakes.

- Always use a tracking number or pay the little extra for delivery signature, guaranteed delivery, or insurance.

- Declare "no value" on customs form.

- Write "Content: Library materials_Books/photocopies" on packages.

\section{CONCLUSION}

Many of the same barriers to international ILL exist today that existed ten years ago. Although advances have been made in citation verification thanks to the growth of the Internet, problems still exist because of decentralized catalogs and language barriers. International ILL is plagued by issues surrounding technology and communications. Cost remains an impediment to the global sharing of resources, especially in the area of returnable items where shipping also plays a role.

U.S. libraries have taken advantage of emerging technology and implemented electronic document delivery as a means of reducing shipping and delivery costs and decreasing turnaround time for nonreturnable items. Consortiasupported courier services also have enabled U.S. libraries to deliver returnable items to libraries within these networks more quickly. These endeavors are particularly strengthened by OCLC WorldCat Resource Sharing and its global efforts toward speedy, user-initiated ILL service. As more libraries become technologically enabled, we need to recognize the technological and economic divides between countries and regions. Although U.S. libraries have taken great strides in promoting cost-effective ILL programs with a few major international library networks, the majority of international ILL requests and their delivery may remain a mediated service because of technological differences.

Regardless of the mutual benefits both U.S. and international libraries receive by employing new document delivery technology, differences in copyright laws and practices across borders will continue to hinder further global interlibrary document delivery. The varying regulations among countries and the rapidly changing information environment make this an area of great concern for both international and domestic ILL. Future work of the committee will also focus on this issue. The RUSA STARS International Interlibrary Loan Committee hopes its work to date has laid a foundation for further initiatives of improving international ILL methods and can spark constructive dialog and discussion within a larger international resource sharing community.

\section{References and Notes}

1. Theresa M. Miguel, "Exchanging Books in Western Europe: A Brief History of International Interlibrary Loan," International Journal of Legal Information 35 (2007): 508-10; Lois C. Gilmer, Interlibrary Loan: Theory and Management (Englewood, Colo.: Libraries Unlimited, 1994): 6-7.

2. Robert A. Seal, "Interlibrary Loan: Integral Component of Global Resource Sharing," Resource Sharing E Information Networks 16, no. 2 (2002): 231-32.

3. RUSA STARS Interlibrary Loan Committee, "Interlibrary Loan Code for the United States," www.ala.org/ala/mgrps/divs/rusa/ resources/guidelines/interlibrary.cfm (accessed May 1, 2009).

4. International Federation of Library Associations and Institutions Section on Document Delivery and Interlending, "International Lending and Document Delivery: Principles and Guidelines for Procedure," www.ifla.org.sg/VI/2/p3/ildd.htm (accessed May 1, 2009).

5. Greater Western Library Alliance Resource Sharing/Document Delivery Committee, Task Force on Interlibrary Loan Best Practices, "Report of the Greater Western Library Alliance Resource Sharing/Document Delivery Committee (GWLA RS/DD)," http:// sites.google.com/a/gwla.org/greater-western-library-alliance/ Committees/RS-DD-Committee-Documents-Archive/bestprac04. doc?attredirects=0 (accessed May 1, 2009).

6. Nancy E. Elkington and Dennis Massie, "The Changing Nature of International Resource Sharing: Risks and Benefits of Collaboration," Interlending \& Document Supply 27, no. 4 (1999): 148-53.

7. Gail Wanner, Anne Beaubian, and Michelle Jeske, "The Rethinking Resource-Sharing Initiative: A New Development in the USA," Interlending \& Document Supply 35, no. 2 (2007): 93.

8. Dennis Massie, "The International Sharing of Returnable Library Materials," Interlending \& Document Supply 28, no. 3 (2000): 112. 
The distribution of libraries provided does not match the total participants. In the Elkington and Massie article referenced, the same discrepancy arises with total participants given as 40 . The authors of this article are unsure of the most accurate participation figures.

9. Elkington and Massie, "The Changing Nature of International Resource Sharing," 151-52.

10. Massie, "The International Sharing of Returnable Library Materials," $110,113$.

11. Elkington and Massie, "The Changing Nature of International Resource Sharing," 150.

12. OCLC, "National Library Participation in the OCLC Global Cooperative," www.oclc.org/us/en/worldcat/catalog/national/default. htm (accessed May 1, 2009).

13. Elkington and Massie, "The Changing Nature of International Resource Sharing," 151.

14. Ibid., 152.

15. Several ILL codes include sections on verification of requests. RUSA's Interlibrary Loan Code for the United States addresses the need for complete bibliographic citations under 4.0, "Responsibilities of the Requesting Library" and IFLA's International Lending and Document Delivery: Principles and Guidelines for Procedures contains a similar section under 4.6.

16. The following national catalogs were mentioned by the majority of respondents: Canada Institute for Scientific and Technical Information (CISTI), http://cisti-icist.nrc-cnrc.gc.ca/eng/ibp/cisti .html; COPAC http://copac.ac.uk; and Karlsruhe Virtual Catalogue (KVK) www.ubka.uni-karlsruhe.de/kvk.html.

17. There are many popular resource-sharing discussion lists available. Some of the most frequently used are ILL-L or OCLC-Sharing-L. ShareILL has a complete listing at www.shareill.org/index.php/ Discussion_lists_and_blogs. ShareILL is a wiki created and maintained by resource-sharing practitioners. It includes assistance for finding aids and tools, managing ILL operations, and keeping abreast of current resource-sharing information (see www.shareill .org/index.php/Main_Page).

18. WorldCat, an Online Computer Library Center (OCLC) program, is frequently used by resource sharing libraries around the world.
More information can be found at www.worldcat.org/whatis/ default.jsp.

19. Gateway Service Center of Chinese Academic Journal Publications, "About the Service," University Library System, University of Pittsburgh, www.library.pitt.edu/libraries/eal/Gateway-Home. htm (accessed May 1, 2009).

20. The Global ILL Framework, "The Global ILL Framework (GIF) Project," North American Coordinating Council on Japanese Library Resources, www.fas.harvard.edu/ ncc/illdd/gifproject html (accessed May 1, 2009).

21. More information can be found at their website: www.bl.uk/ welcome/librarians.html.

22. DOCLINE, "DOCLINE System," National Library of Medicine, www.nlm.nih.gov/docline/ (accessed May 1, 2009)

23. Canada Institute for Scientific and Technical Information (CISTI), http://cisti-icist.nrc-cnrc.gc.ca/eng/ibp/cisti.html (accessed May 1, 2009); COPAC, http://copac.ac.uk; and Karlsruhe Virtual Catalogue (KVK) www.ubka.uni-karlsruhe.de/kvk.html (accessed May 1, 2009).

24. More information on the ISO ILL Protocol can be found at: ISO ILL, "An Introduction to the ISO InterLibrary Loan Application Standards," Interlibrary Loan Application Standards Maintenance Agency, www.collectionscanada.gc.ca/iso/ill/standard.htm.

25. Christine Robben and Cherié Weible, "International Payment: Methods to Consider," Journal of Interlibrary Loan, Document Delivery E Information Supply 12, no. 3 (2002): 29-35.

26. FreeShare is a group of DOCLINE-participating libraries that agree to fill each other's DOCLINE requests free of charge. See http://nnlm.gov/rsdd/freeshare.

27. Mary Jackson with Bruce Kingma and Tom Delaney, Assessing ILL/ DD Services: New Cost-Effective Alternatives (Chicago: Association of Research Libraries, 2004): 31-37.

28. Ibid., 24.

29. Massie, "The International Sharing of Returnable Library Materials," 110.

30. Ibid

31. Ibid., 111.

32. Ibid., 114-15.

\section{BEST OF THE BEST CONTINUED FROM PAGE 53}

One major highlight of the website is the Small Business Planner, which is a one-stop toolkit that includes resources and information for the small business owner, including an online workshop and materials on business planning, support for business growth, and information about the SBA's financial assistance program.

In addition to information, the site also provides ways to find mentors and connect with other small business owners via online chat forums and events, and provides a link to SCORE, "Counselors to America's Small Business," an organization that connects retired small business owners who serve as mentors for new business owners. There are also a number of online training opportunities available.
The site's other valuable tools include online chats, podcasts and videos, reports and statistics on small business topics, and information about regional SBA offices. One can also subscribe to a variety of e-newsletters and find out about local small business events.

The SBA website is easy to use, contains free information, and provides added value via links to other solid resources and support. It would be valuable for anyone considering starting their own business as well as more seasoned business owners, and serves as an excellent starting point for researchers who need information and data about small business topics.-Penny Scott, Reference Librarian and Business Liaison, University of San Francisco 